\title{
Recent trends in atmospheric methyl bromide: analysis of post-Montreal Protocol variability
}

\author{
S. A. Yvon-Lewis ${ }^{1}$, E. S. Saltzman ${ }^{2}$, and S. A. Montzka ${ }^{3}$ \\ ${ }^{1}$ Department of Oceanography, Texas A\&M University, College Station, TX 77843, USA \\ ${ }^{2}$ Department of Earth System Science, University of California Irvine, Irvine, CA 92697, USA \\ ${ }^{3}$ Global Monitoring Division, NOAA/ESRL, Boulder, CO 80305, USA
}

Received: 9 February 2009 - Published in Atmos. Chem. Phys. Discuss.: 10 March 2009

Revised: 26 June 2009 - Accepted: 23 July 2009 - Published: 19 August 2009

\begin{abstract}
The atmospheric methyl bromide $\left(\mathrm{CH}_{3} \mathrm{Br}\right)$ burden has declined in recent years, in response to the phaseout of agricultural and structural fumigation consumption under the amendments to the Montreal Protocol. The timing and magnitude of this decrease represents an opportunity to examine our current understanding of atmospheric $\mathrm{CH}_{3} \mathrm{Br}$ and its budget, response to the phaseout, and response to interannual variability in biomass burning and global $\mathrm{OH}$. In this study, simulations obtained from a time-dependent global model of atmospheric $\mathrm{CH}_{3} \mathrm{Br}$ emissions and uptake are compared to observations from the NOAA flask network. The model includes a detailed gridded ocean model coupled to a time-dependant atmospheric 2-box model. The phaseout of $\mathrm{CH}_{3} \mathrm{Br}$ production for agricultural uses began in 1998, concurrent with the pulse in biomass burning associated with the 1998 El Niño. The combined effects of three factors (biomass burning, global $\mathrm{OH}$, and anthropogenic phaseout) appear to explain most of the observed atmospheric methyl bromide variability over the 1997-2008 period. The global budget remains imbalanced, with a large missing source indicated. The missing source does not exhibit a systematic decline during the phaseout period, and therefore, is not the result of significantly underestimating non-QPS agricultural $\mathrm{CH}_{3} \mathrm{Br}$ emissions. The model results suggest that the oceans should be less undersaturated than before the phaseout began.
\end{abstract}

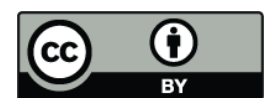

Correspondence to: S. A. Yvon-Lewis (syvon-lewis@ocean.tamu.edu)

\section{Introduction}

$\mathrm{CH}_{3} \mathrm{Br}$ is a stratospheric ozone depleting substance that, unlike many other ozone-depleting compounds, has both natural and anthropogenic sources. The use of $\mathrm{CH}_{3} \mathrm{Br}$ as an agricultural fumigant has been reduced according to the amendments to the Montreal Protocol (UNEP, 1995), and phaseout began in 1998. Although many sources and sinks of $\mathrm{CH}_{3} \mathrm{Br}$ have been identified and quantified, the global budget of atmospheric $\mathrm{CH}_{3} \mathrm{Br}$ for the pre-phaseout atmosphere is not balanced (Montzka and Fraser et al., 2003). The best estimate of the annual global budget for 1996 had an imbalance of nearly $37 \mathrm{Gg}$ between sources and sinks (Table 1). This imbalance is clearly a result of our incomplete knowledge, rather than a real difference between sources and sinks, because the atmosphere was not rapidly changing at that time (Yokouchi et al, 2002; Montzka et al., 2003). The imbalance may reflect uncertainty in both natural and anthropogenic components of the budget. Knowledge of the emissions from terrestrial plants and ecosystems is quite limited (Montzka and Fraser et al., 2003; Gan et al., 1998; Dimmer et al., 2001; Redecker et al., 2000; Rhew et al., 2001; Varner et al., 1999). Even the anthropogenic emissions of $\mathrm{CH}_{3} \mathrm{Br}$ from agricultural fumigation are not easily quantified, since soil uptake during fumigation can be significant, and may vary with soil conditions and application technique (MBTOC, 2006).

The decline in atmospheric $\mathrm{CH}_{3} \mathrm{Br}$ burden resulting from the phaseout of agricultural emissions presents an opportunity to test our understanding of global $\mathrm{CH}_{3} \mathrm{Br}$ cycling. Yokouchi et al. (2002) and Montzka et al. (2003) detected the atmospheric decline using measurements from flask air networks. Those authors, as well as Reeves (2003), noted that the initial decline during 1998-2002 was roughly twice

Published by Copernicus Publications on behalf of the European Geosciences Union. 


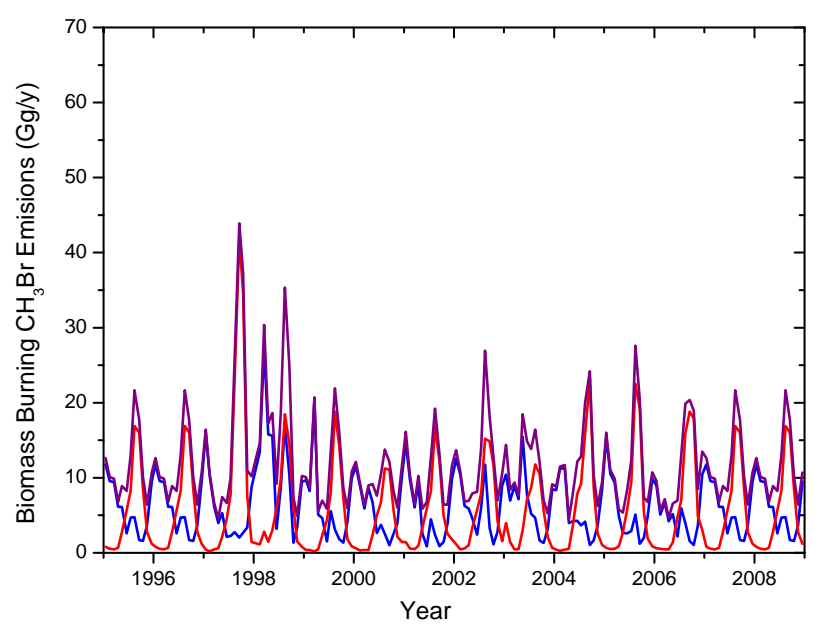

Fig. 1. The trend in biomass burning emissions of $\mathrm{CH}_{3} \mathrm{Br}$ for the southern hemisphere (red line), the northern hemisphere (blue line), and the globe (purple line). Prior to 1997 and after 2006, the biomass burning emissions are shown as the monthly averages of the 1997-2006 data excluding the highest and lowest values for a given month (van der Werf et al., 2005 and updates from http://ess1.ess.uci.edu/\$ $\backslash$ sim\$jranders/data/GFED2/).

as large as expected. They suggested that the observations could be explained if the anthropogenic component of the total emissions was larger than previously thought. This assertion also required an atmospheric lifetime $\geq 14 \%$ longer than the best estimate of $0.7 \mathrm{yr}$ based on the known $\mathrm{CH}_{3} \mathrm{Br}$ sinks (reaction with $\mathrm{OH}$, photolysis, uptake by the ocean, and uptake by soils) (Yvon-Lewis and Butler, 1997). In this study, we revisit the atmospheric decline during phaseout using a slightly longer data set, covering 1995-2008 (Montzka et al., 2003 - with updates from NOAA/GMD urlftp://ftp.cmdl.noaa.gov/hats/methylhalides/ch3br/flasks/), and an updated, time-dependent global model of $\mathrm{CH}_{3} \mathrm{Br}$ emissions and uptake.

\section{Global model, budget and data sources}

This study of the seasonal and interannual variations in atmospheric $\mathrm{CH}_{3} \mathrm{Br}$ was carried out using a numerical model that simulates the major processes involved in the global biogeochemical cycle of $\mathrm{CH}_{3} \mathrm{Br}$, including oceanic production and consumption, soil uptake, terrestrial plant emissions, fumigation, gasoline combustion, biomass burning, biofuel emissions, atmospheric loss via reaction with $\mathrm{OH}$ and photolysis in the stratosphere. The model is described in detail by Saltzman et al. (2004). It consists of two well-mixed atmospheric boxes representing northern and southern hemispheres. Transport between the hemispheres is governed by an interhemispheric exchange time constant of 1 year. Surface fluxes of methyl bromide are seasonally and spatially variable. For the oceans, monthly, $1^{\circ} \times 1^{\circ}$, average ocean parameters from the NOAA/GFDL Global Oceanographic Data Set Atlas (available at http://dss.ucar.edu/ datasets/ds279.0) were used to characterize oceanic temperatures, salinities, mixed layer depths, and $10 \mathrm{~m}$ wind speeds. Oceanic $\mathrm{CH}_{3} \mathrm{Br}$ production rates are specified based on the observed saturation state of the pre-phaseout ocean extrapolated on the basis of the saturation anomaly vs. SST relationship identified in King et al. (2002). Each surface ocean cell maintains a mass balance for $\mathrm{CH}_{3} \mathrm{Br}$ and interacts independently with the atmosphere. Land surface sources and sinks are distributed using the International Satellite Land Surface Climatology Project (ISLSCP) (Meeson et al., 1995; Sellers et al., 1995) and Matthews (1983) databases as described in Saltzman et al. (2004).

The pre-phaseout source and sink fluxes incorporated here are shown in Table 1 and reflect a revision in the budget described by Montzka and Fraser (2003). The sinks and corresponding oceanic emission terms were adjusted for the revised tropospheric burden of $125 \mathrm{Gg}$ (atmospheric burden $132 \mathrm{Gg}$ ) observed in 1996 (Montzka et al., 2003 with updates from NOAA/GMD ftp://ftp.cmdl.noaa. gov/hats/methylhalides/ch3br/flasks/). Separate peatland and rice paddy emissions are not shown as the databases do not distinguish them from wetlands (Saltzman et al., 2004). Biofuel emissions were added, and seasonal variations in biomass burning were included. This budget is not balanced, and the missing source implied from this imbalance is discussed below. The details of the sources and sinks used in this model are described in Saltzman et al. (2004). Changes made since then are discussed below.

Monthly fire distributions for 1997-2006 were determined from satellite observations by van der Werf et al. (2006) with subsequent updates (http://ess1.ess.uci.edu/+-jranders/data/ GFED2/). $\mathrm{CH}_{3} \mathrm{Br}$ emissions from these fires are scaled to the $\mathrm{CO}$ fluxes calculated for the fires using emissions factors from Andreae and Merlet (2001). The resulting annual average $\mathrm{CH}_{3} \mathrm{Br}$ emissions from biomass burning for 1997-2006 range from 11 to $16 \mathrm{Gg} \mathrm{yr}^{-1}$. This range is lower than the previous best estimate of $20 \mathrm{Gg}$ for biomass burning emissions in the Montzka and Fraser (2003) budget. There is an initial increase in biomass burning emission in 1998 with a subsequent decline in emissions through 2004 (Fig. 1, Table 2). For the model simulations prior to 1997 and after 2006, the biomass burning emissions used are the monthly averages of the 1997-2006 data excluding the highest and lowest values for a given month.

The pseudo first order loss rate constant for $\mathrm{CH}_{3} \mathrm{Br}$ by reaction with $\mathrm{OH}$ was computed using the temperaturedependent rate constant from Sander et al. (2006) and the $\mathrm{OH}$ and temperature fields from Spivakovsky et al. (2000). The pseudo first order rate constants are averaged for each hemispheric troposphere for each month to generate a seasonal hemispheric $\mathrm{OH}$ sink for $\mathrm{CH}_{3} \mathrm{Br}$. Interannual variability in global $\mathrm{OH}$ is simulated (Fig. 2, Table 2) by scaling $\mathrm{OH}$ in the 
Table 1. Global $\mathrm{CH}_{3} \mathrm{Br}$ budgets for 1996 and 2007. The 1996 budget is modified from Montzka and Fraser et al. (2003) and Clerbaux and Cunnold et al. (2007). The italicized numbers highlight budget terms that changed between 1996 and 2007. Superscripts indicate references.

\begin{tabular}{llll}
\hline & \multicolumn{3}{l}{ Best Estimate $(\mathrm{Gg} / \mathrm{y})$} \\
& Pre-Phaseout & Pre-Phaseout & Recent \\
& 1996 & $1996(60 \% \mathrm{Ag})^{\S}$ & $2007(60 \% \mathrm{Ag})^{\S}$ \\
\hline Sources & & & \\
Ocean & $42.0^{*, 1}$ & $42.0^{*, 1}$ & $42.0^{* *}$ \\
Fumigation-Quarantine and Preshipment & $12.3^{2}$ & $12.3^{2}$ & $13.82^{3}$ \\
Fumigation-Soils and Other & $31.0^{3}$ & $36.6^{3}$ & $5.2^{3}$ \\
Gasoline & $5.7^{4}$ & $5.7^{4}$ & $5.7^{4}$ \\
Biomass Burning & $11.3^{5,6}$ & $11.3^{5,6}$ & $11.3^{5,6}$ \\
Biofuel & $6.1^{6,7}$ & $6.1^{6,7}$ & $6.1^{6,7}$ \\
Wetlands & $4.6^{8}$ & $4.6^{8}$ & $4.6^{8}$ \\
Salt marshes & $14.6^{9}$ & $14.6^{9}$ & $14.6^{9}$ \\
Shrublands & $10^{10}$ & $1^{10}$ & $1^{10}$ \\
Rapeseed & $6.6^{11}$ & $6.6^{11}$ & $6.6^{5}$ \\
Fungus & $1.7^{12}$ & $1.7^{12}$ & $1.7^{12}$ \\
Subtotal Sources & 137 & 143 & 113 \\
Sinks & & & \\
Ocean & & & $-43^{12}$ \\
OH and hv & $-56^{13,14}$ & $-56^{13,14}$ & $-48.6^{13,14}$ \\
Soils & $-77^{14,15}$ & $-77^{14,15}$ & $-63.6^{14,15,16}$ \\
Plants & $-41^{14,17}$ & $-41^{14,17}$ & $-34.0^{14,17}$ \\
Subtotal Sinks & - & - & -146 \\
Total (Sources+Sinks) & -174 & -174 & $-32^{* * *}$ \\
\hline
\end{tabular}

$\S$ The $60 \%$ Ag refers to the change from $50 \%$ emission during fumigation to $60 \%$ emission (scenario 8 ).

${ }^{1}$ King et al. (2002), ${ }^{2}$ Buffin (2004), ${ }^{3}$ MBTOC (2006), ${ }^{4}$ Thomas et al. (1997), ${ }^{5}$ van der Werf et al. (2006)

${ }^{6}$ Andreae and Merlet (2001), ${ }^{7}$ Yevich and Logan (2003), ${ }^{8}$ Varner et al. (1999), ${ }^{9}$ Rhew et al. (2000)

${ }^{10}$ Rhew et al. (2001), ${ }^{11}$ Gan et al. (1998), ${ }^{12}$ Lee-Taylor and Holland (2000), ${ }^{13}$ Yvon-Lewis and Butler (2002)

${ }^{14}$ Saltzman et al. (2004), ${ }^{15}$ Spivakovsky et al. (2000), ${ }^{16}$ Prinn et al. (2005), ${ }^{17}$ Shorter et al. (1995)

*Net ocean flux $=-14.0 \mathrm{Gg} / \mathrm{y}$

$* *$ Net ocean flux $=-6.6 \mathrm{Gg} / \mathrm{y}$

*** Assumed to be a natural missing source

model to the variations inferred by Prinn et al. (2005) through 2003 from the ALE-GAGE network measurements of methyl chloroform. According to those estimates, global $\mathrm{OH}$ decreased by approximately 13\% during 1997/1998 compared to other years, though such large changes are not consistent with observations of other trace gases during this period, such as $\mathrm{CH}_{4}$ (Lelieveld et al., 2006). After 2003, the model retains the $2003 \mathrm{OH}$ levels and seasonality.

Previous modeling studies do not include emissions from combustion of biofuels. However, they were included in the most recent budget estimate (Clerbaux and Cunnold, 2007). While some of these emissions can be accounted for through the satellite fire database described for the biomass burning emission distributions, the emissions associated with burning of biofuels inside houses and structures cannot be observed from satellites. Emissions from biofuels, minus the outdoor burning that would be a part of the biomass burning calculations, equal approximately $6.1 \mathrm{Gg} \mathrm{y}^{-1}$ and are primarily in the northern hemisphere (Andreae and Merlet, 2001; Yevich and Logan, 2003). The biofuel emissions were determined for each country with a $20 \%$ increase for developing countries to bring the emissions to a value appropriate for 1995 according to Yevich and Logan (2003) and those emissions were then sorted into their respective hemispheres resulting in emissions of $5.2 \mathrm{Gg} \mathrm{yr}^{-1} \mathrm{CH}_{3} \mathrm{Br}$ in the northern hemisphere (NH) and $0.9 \mathrm{Gg} \mathrm{yr}^{-1}$ in the southern hemisphere (SH). Yevich and Logan (2003) caution that their biofuel emission estimates could have an uncertainty of $\pm 50 \%$. This uncertainty directly applies to the $\mathrm{CH}_{3} \mathrm{Br}$ emissions from biofuels, as we used emission factors from Andrea and Merlet (2001) to convert the Yevich and Logan (2003) biofuel emissions to $\mathrm{CH}_{3} \mathrm{Br}$ emissions. 
Table 2. Annual global biomass burning emissions, consumption for non-QPS fumigation, and the pseudo first order rate constant for reaction with $\mathrm{OH}$.

\begin{tabular}{cccc}
\hline Year & $\begin{array}{c}\text { Biomass Burning } \\
(\mathrm{Gg})\end{array}$ & $\begin{array}{c}\text { Non-QPS Fumigation } \\
(\mathrm{Gg})\end{array}$ & $\begin{array}{c}\mathrm{K}[\mathrm{OH}]^{3,4} \\
\left(\mathrm{yr}{ }^{-1}\right)\end{array}$ \\
\hline 1995 & 11.3 & 61.0 & 0.56 \\
1996 & 11.3 & 61.0 & 0.56 \\
1997 & 15.9 & 61.0 & 0.49 \\
1998 & 17.0 & 58.2 & 0.52 \\
1999 & 11.2 & 47.4 & 0.52 \\
2000 & 9.7 & 40.8 & 0.53 \\
2001 & 10.5 & 34.3 & 0.55 \\
2002 & 12.0 & 25.6 & 0.55 \\
2003 & 11.4 & 21.4 & 0.54 \\
2004 & 11.6 & 26.1 & 0.54 \\
2005 & 11.8 & 16.7 & 0.54 \\
2006 & 11.2 & 13.8 & 0.54 \\
2007 & 11.3 & 8.7 & 0.54 \\
2008 & 11.3 & 8.7 & 0.54 \\
\hline
\end{tabular}

1 van der Werf et al. (2006)

${ }^{2}$ MBTOC (2006) in years after 1997; assumed constant at $61 \mathrm{Gg} / \mathrm{yr}$ from 1995-1997

${ }^{3}$ Spivakovsky et al. (2000)

${ }^{4}$ Prinn et al. (2005)

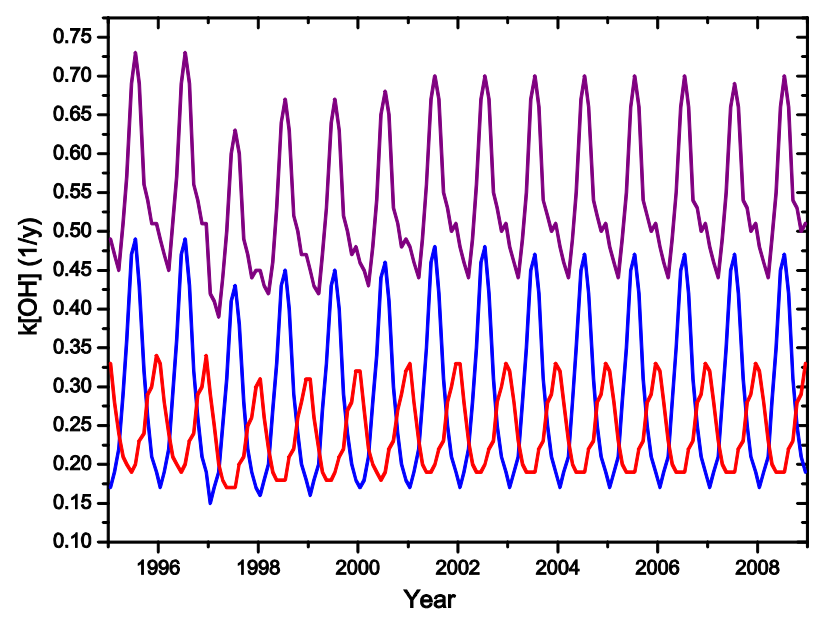

Fig. 2. The trend in the pseudo first order loss rate constant for loss of $\mathrm{CH}_{3} \mathrm{Br}$ to reaction with $\mathrm{OH}$ for the southern hemisphere (red line), the northern hemisphere (blue line), and the globe (purple line). For model years $1997-2003$, OH is scaled by the interannual variations given by Prinn et al. (2005). For the remainder of the simulation, the $2003 \mathrm{OH}$ scaling factor was used.

The total industrially-derived emissions from fumigation of soils, durables, perishables, and structures was $43.3 \mathrm{Gg} \mathrm{yr}^{-1}$ ( $\sim 25 \%$ of total emissions including the missing source) in 1996 (Table 1). For this study, it is assumed that consumption equal use and stockpiling is not considered. The hemispheric distribution, seasonality, and annual

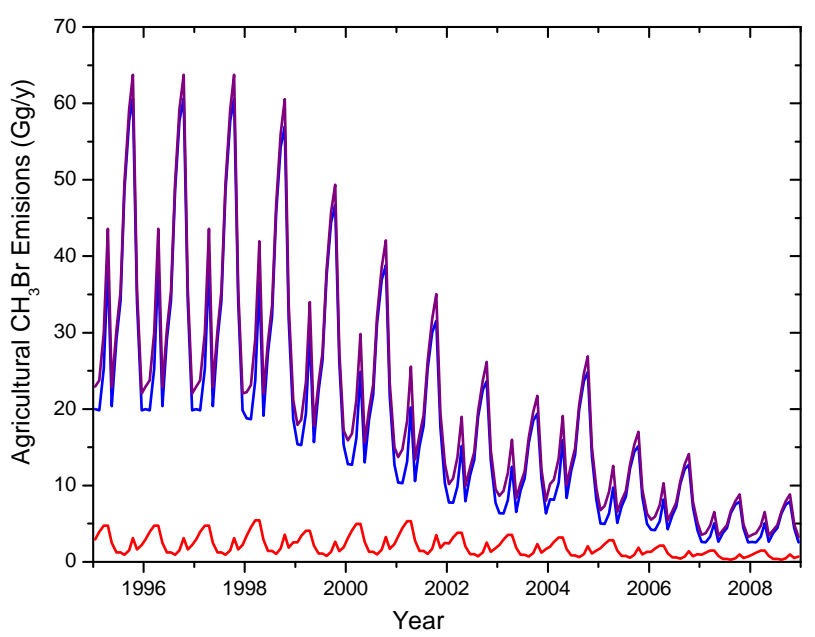

Fig. 3. The trend in non-QPS agricultural emissions of $\mathrm{CH}_{3} \mathrm{Br}$, assuming 50\% of consumption is emitted, from 1995 through 2008 for the southern hemisphere (red line), the northern hemisphere (blue line), and the globe (purple line).

trend of the non-quarantine and preshipment (non-QPS) fumigation source are based on government and industry statistics on consumption (MBTOC, 2006) (Fig. 3, Table 2) with agricultural soil emissions maintained at 2005 values after that time. The quarantine and preshipment (QPS) emissions remained constant at $12.3 \mathrm{Gg} \mathrm{yr}^{-1}$ from 1995 through 1998 (Buffin, 2004). The trend in QPS emissions from 1999 through 2005 is based on the QPS trends reported in MBTOC (2006). These data suggest an increase in QPS emissions in 2005 that reflected the increased use to meet new guidelines for regulating wood products in international trade (IPPC, 2002; Federal Register, 2004). The elevated 2005 values were maintained for the remainder of the simulation time (e.g. 2007, Table 1).

\section{Results and discussion}

\subsection{Model initialization and scenarios}

The model is initialized by running it for several years with the $1996 \mathrm{CH}_{3} \mathrm{Br}$ budget and Spivakovsky et al. (2000) $\mathrm{OH}$ levels, until a repeatable annual cycle in atmospheric $\mathrm{CH}_{3} \mathrm{Br}$ is obtained. As noted earlier, there is a significant imbalance in the "best estimate" $\mathrm{CH}_{3} \mathrm{Br}$ budget (Table 1), with atmospheric losses exceeding the known sources by $\sim 37 \mathrm{Gg} \mathrm{yr}^{-1}$ after adjusting to the $125 \mathrm{Gg}$ tropospheric burden. With the inter tropical convergence zone (ITCZ) located at the equator, the magnitude and seasonality of the unknown source(s) were adjusted in the model by trial and error to achieve agreement with the mean 1995-1998 tropospheric hemispheric mixing ratios $(\mathrm{NH}=10.2 \mathrm{ppt}, \mathrm{SH}=8.0 \mathrm{ppt})$ and seasonalities (Montzka et al., 2003) (Fig. 4a). This resulted in annually 
Table 3. Model scenarios used in this study. If not explicitly stated, sources and sinks are maintained as in the 1996 model year.

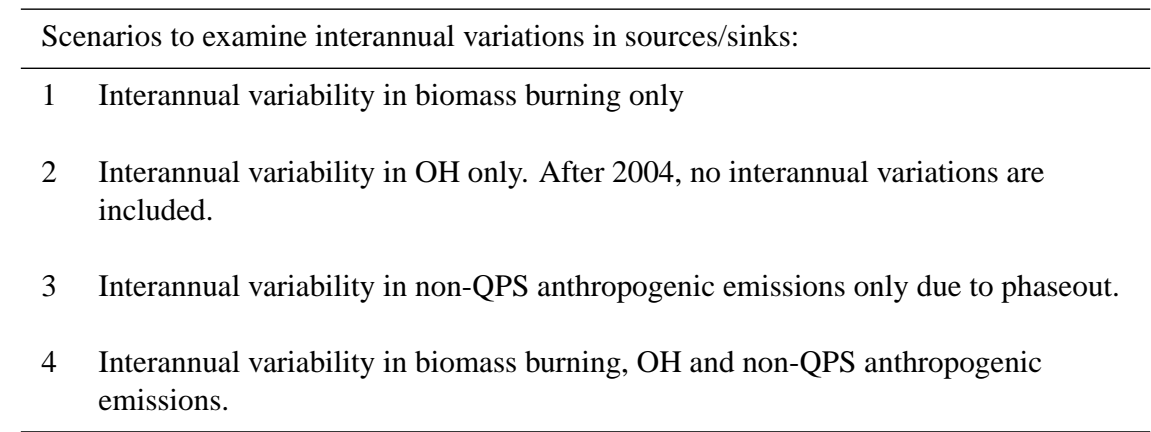

Scenarios to examine missing source and atmospheric lifetime:

5 Missing source term treated as agricultural emissions and allowed to decrease with phaseout. Interannual variability in biomass burning, $\mathrm{OH}$ and non-QPS anthropogenic emissions included.

6 Missing source reduced by $50 \%$, and atmospheric lifetime of $\mathrm{CH}_{3} \mathrm{Br}$ increased to 0.84 yr. Remaining missing source adjusted to match the observed pre-phaseout seasonality and treated as agricultural. Interannual variability in biomass burning, $\mathrm{OH}$ and non-QPS anthropogenic emissions included.

7 Missing source reduced by $50 \%$, and atmospheric lifetime of $\mathrm{CH}_{3} \mathrm{Br}$ increased to 0.84 yr. Remaining missing source adjusted to match the observed pre-phaseout seasonality and treated as natural with no interannual variability. Interannual variability in biomass burning, $\mathrm{OH}$ and non-QPS anthropogenic emissions included.

8 Agricultural emissions increased to $60 \%$, and atmospheric lifetime kept as it was in scenarios 1-5. Missing source reduced by the amount of the agricultural increase. Interannual variability in biomass burning, OH and non-QPS anthropogenic emissions included.

averaged emissions for the unknown source of $\sim 19 \mathrm{Gg} \mathrm{yr}^{-1}$ in the northern hemisphere and $\sim 17 \mathrm{Gg} \mathrm{yr}^{-1}$ in the southern hemisphere. This approach is the same as that used in Saltzman et al. (2004), with only slightly different emissions being derived for this unknown source.

Simulations were run to examine the sensitivity of the location of the "missing source" to the position of the model ITCZ. Moving the ITCZ in the model northward from the equator to $5 \mathrm{~N}$ shifts the missing source almost entirely to the southern hemisphere. This is a consequence of shifting a significant fraction $(\sim 20 \%)$ of the $\mathrm{OH}$ sink in the $\mathrm{NH}$ to the $\mathrm{SH}$. In the $5 \mathrm{~N}$ ITCZ case, it is not possible to simulate the observed amplitude of $\mathrm{NH}$ seasonal variations in $\mathrm{CH}_{3} \mathrm{Br}$ because there is no missing source with which to adjust $\mathrm{NH}$ seasonality. Further studies of this type should be carried out using 3-D transport models that are capable of more realistic simulation of interhemispheric mixing.
This model reproduces pre-phaseout atmospheric observed seasonal variations quite well, considering the crude seasonal parameterizations for the terrestrial sources and soil sink, and the fact that interhemispheric exchange is based on mean hemispheric levels. While the lack of atmospheric dynamics in this model precludes investigation of the spatial distribution of the missing source, the model can be used to examine the nature of the missing source through interannual variations in sources and sinks and the impact of a change in lifetime on the seasonal variations and interannual trends.

Eight model scenarios are discussed here (Table 3). The first four cases are used to examine the impact of interannual variations in selected sources and sinks. The calculated hemispheric missing source strengths and seasonalities were fixed for the duration of Scenarios 1-4. Scenarios 58 are used to examine the nature of the missing source and the possibility of a longer atmospheric lifetime for $\mathrm{CH}_{3} \mathrm{Br}$. The model is also used to investigate the impact of the atmospheric variability on the saturation state of the ocean. 

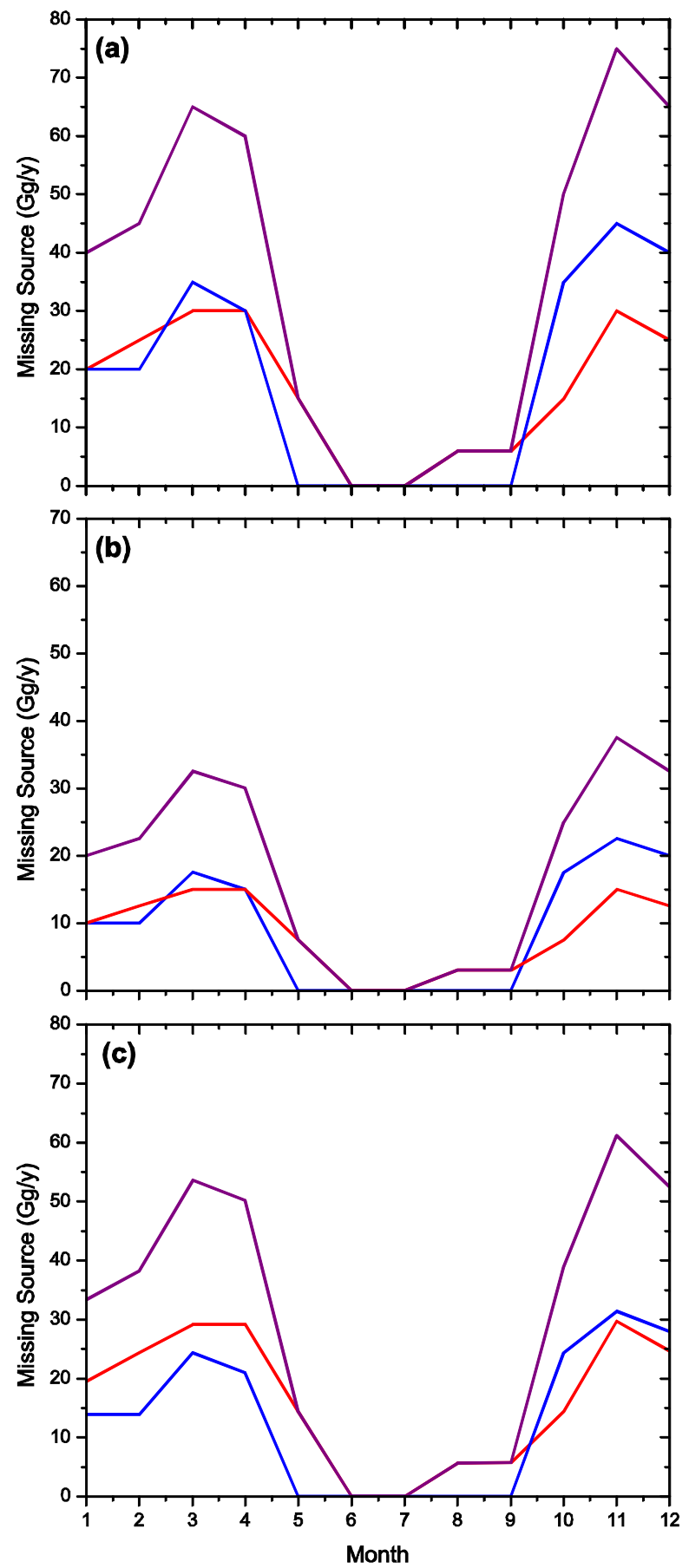

Fig. 4. Seasonal cycle in the missing source for the southern hemisphere (red line), the northern hemisphere (blue line), and the globe (purple line) for (a) scenarios 1-4, (b) scenario 7 and (c) scenario 8.

\subsection{Interannual Variabity in biomass burning, atmo- spheric $\mathrm{OH}$, and anthropogenic $\mathrm{CH}_{3} \mathrm{Br}$ emissions}

The first scenario examines the impact of interannual variability in biomass burning $\mathrm{CH}_{3} \mathrm{Br}$ emissions on the atmospheric $\mathrm{CH}_{3} \mathrm{Br}$ burden (Table 3, Fig. 5). During the 19971998 period, the emissions from biomass burning increased by $3.0 \mathrm{Gg} \mathrm{y}^{-1}(\mathrm{NH})$ and $5.6 \mathrm{Gg} \mathrm{y}^{-1}(\mathrm{SH})$ over the mean values used for the pre-phaseout conditions (Fig. 1, Table 2). This case yields an increase in the annually averaged atmospheric $\mathrm{CH}_{3} \mathrm{Br}$ of $0.27 \mathrm{ppt}(\mathrm{NH})$ and $0.26 \mathrm{ppt}(\mathrm{SH})$ over the mid-1997 to mid-1998 period that is consistent with the observations. The effect of increased biomass burning was much larger (on a relative basis) in the southern hemisphere, both because the increase in emissions was larger than in the northern hemisphere, and because biomass burning is a larger fraction of the total emissions in the southern hemisphere. Given the mean lifetime of about 0.7 years, roughly one third of the emissions in each hemisphere are transported to the other hemisphere. As noted by Saltzman et al. (2004) the approach of using hemispherically averaged atmospheric boxes may underestimate the interhemispheric mixing of low latitude sources, like biomass burning. Hemispheric averaging also undoubtedly slightly overestimates the atmospheric lifetime of low latitude emissions which are released in the region of highest $\mathrm{OH}$ and atmospheric reactivity.

The second scenario examines the effect of interannual variability in global $\mathrm{OH}$ (Table 3, Fig. 5). Model $\mathrm{OH}$ levels are fixed at the Spivakovsky et al. (2000) values from 19951996. For model years $1997-2003$, OH loss is scaled by the interannual variations given by Prinn et al. (2005) (Fig. 2, Table 2). For the remainder of the simulation, the $2004 \mathrm{OH}$ scaling factor was used. The decline in $\mathrm{OH}$ concentrations during 1998 results in a noticeable increase in the atmospheric burden of $\mathrm{CH}_{3} \mathrm{Br}$. The subsequent increase in $\mathrm{OH}$ back to pre-1998 values results in a decrease and subsequent leveling off of the atmospheric $\mathrm{CH}_{3} \mathrm{Br}$.

The third scenario examines the effect of anthropogenic phaseout (Table 3, Fig. 5). The phaseout imposed by the Montreal Protocol and its amendments resulted in a nearly $86 \%$ reduction in emissions from regulated non-QPS agricultural fumigation applications from the 1996 budget to 2007 . Critical Use Exemptions (CUEs) in non-QPS applications have allowed the emissions to decrease at a slower rate than originally specified by the amendments to Montreal Protocol (Fig. 3, Table 2). For this model case, biomass burning was fixed at the 1996 values for the entire run, and $\mathrm{OH}$ loss was maintained at the 1995-1996 values. The model results show that the decline in anthropogenic emissions results in a significant decline in atmospheric $\mathrm{CH}_{3} \mathrm{Br}$ levels from 1996 to 2007. The phaseout alone appears to account for most of the overall change in atmospheric burden from 1996 to 2007. However, this scenario does not accurately capture the initial increase in $\mathrm{CH}_{3} \mathrm{Br}$ in 1997/1998, and it does not result in low enough atmospheric values in 2007. 

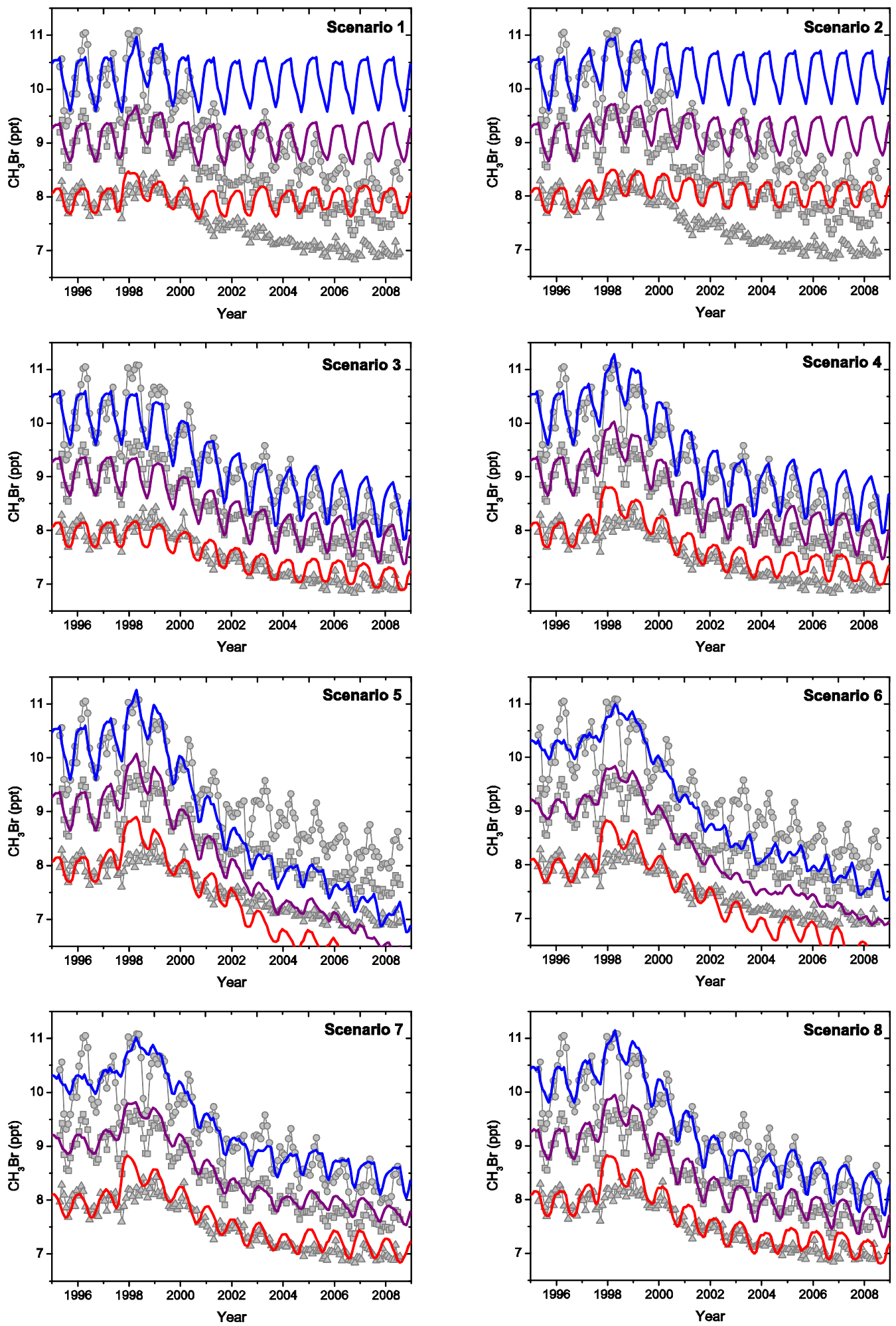

Fig. 5. Modeled and measured trends in atmospheric $\mathrm{CH}_{3} \mathrm{Br}$ concentrations for 1995-2008. In all plots, the data points for Southern Hemisphere $(\triangle)$, the Northern Hemisphere $(\bigcirc)$, and the globe $(\square)$ are observations from NOAA/GMD (ftp://ftp.cmdl.noaa.gov/hats/ methylhalides/ch3br/flasks/). Model results are shown for the southern hemisphere (red line), the northern hemisphere (blue line), and the globe (purple line) for the scenarios described in Table 3. 
The fourth scenario examines the combined effect of interannual variability in biomass burning, $\mathrm{OH}$, and anthropogenic phaseout (Table 3, Fig. 5). This case does a good job of simulating northern hemisphere variability, capturing both the 1998 increase and subsequent decline of $\mathrm{CH}_{3} \mathrm{Br}$. In the southern hemisphere, the simulation overestimates the initial increase in $\mathrm{CH}_{3} \mathrm{Br}$ during late 1997 and early 1998. After the peak, southern hemispheric levels in the model run decreased rapidly, bringing the simulation back into agreement with the atmospheric measurements for several years. From 2004 through 2007, the model shows a leveling off of southern hemisphere $\mathrm{CH}_{3} \mathrm{Br}$ levels, while the atmospheric measurements show a continued decline until 2007. The overestimates in the SH in 1997/8 and after 2004 could both be a result of the distributions of biomass burning near the equator and the location of the ITCZ in the model calculation.

One of the limitations of this study is the inability to evaluate other biogeochemical impacts of the 1998 El Niño or other natural variations on other $\mathrm{CH}_{3} \mathrm{Br}$ sources and sinks. In particular, the droughts associated with the El Niño could have significantly affected both terrestrial emissions and the soil sink. Widespread changes in carbon cycling occurred as a result of the $1998 \mathrm{El}$ Niño, as evidenced by the subsequent increase in atmospheric $\mathrm{CO}_{2}$. Increased $\mathrm{CO}_{2}$ at that time was caused, at least in part, by a decrease in vegetative growth and an increase in soil respiration (Cramer et al., 2001; Nemani et al., 2003; Erbrecht and Lucht, 2006). However, there is insufficient information at present with which to assess how such changes affected $\mathrm{CH}_{3} \mathrm{Br}$ cycling.

The results discussed above suggest that the initial phaseout began right after elevated background $\mathrm{CH}_{3} \mathrm{Br}$ mixing ratios were observed as a result of the combined increase in biomass burning associated with the $1998 \mathrm{El}$ Niño (van der Werf et al., 2004) and the decrease in $\mathrm{OH}$ associated with the increased biomass burning emissions. This caused the initial decrease in $\mathrm{CH}_{3} \mathrm{Br}$ associated with the phaseout to appear larger than expected from the change in agricultural emissions. By accounting here for these non-anthropogenic influences, having additional years of data to analyze during which such perturbations were diminished, and incorporating a revised calibration for the $\mathrm{NOAA} \mathrm{CH}_{3} \mathrm{Br}$ data a more robust accounting of industrially-derived $\mathrm{CH}_{3} \mathrm{Br}$ in the atmosphere is possible. This analysis is consistent with a ratio of anthropogenic to total emissions of $\sim 25 \%$, or fairly close to the updated estimate of $30(20-40) \%$ in Clerbaux and Cunnold (2007).

\subsection{The "Missing $\mathrm{CH}_{3} \mathrm{Br}$ Source" and atmospheric $\mathrm{CH}_{3} \mathrm{Br}$ lifetime}

The model results discussed above demonstrate that the major features of the recent variability in atmospheric $\mathrm{CH}_{3} \mathrm{Br}$ can be reasonably well simulated by simultaneously imposing interannual variability in biomass burning, global $\mathrm{OH}$, and anthropogenic emissions on the 1996 best-estimate global budget including an unknown seasonally varying natural source that exhibits no interannual variability (Fig. 5). However, there are still biases in the model results.

The cause of the imbalance between sources and sinks is one of the most puzzling aspects of the global $\mathrm{CH}_{3} \mathrm{Br}$ budget. This imbalance has persisted for more than a decade in all global budgets, despite continued research on both sources and sinks. It is generally suspected that the missing source is related to emissions from terrestrial vegetation. The modeling results of Warwick et al. (2006) suggest that the missing source could be from a combination of tropical and subtropical plants and biomass burning. To date, only limited emissions surveys from terrestrial plants and ecosystems have been carried out, and it can be argued that the seasonality of these sources is not well documented (Montzka and Fraser et al., 2003; Gan et al., 1998; Dimmer et al., 2001; Redecker et al., 2000; Rhew et al., 2001; Varner et al., 1999).

In model scenarios 5-8, the magnitude and nature of the missing source is examined beginning with the thesis of Yokouchi et al. (2002) and Montzka et al. (2003). After they detected the rapid decline in atmospheric $\mathrm{CH}_{3} \mathrm{Br}$ from 1998 to 2002 , they suggested that the rapid decline could indicate that the anthropogenic component of the budget was larger than previously thought. This required either an upward revision of the anthropogenic emissions (as part or all of the missing source) or an upward revision of the atmospheric lifetime to $\geq 0.8 \mathrm{yr}$ (Montzka et al., 2003) from the current best estimate of $0.7 \mathrm{yr}$ (Yvon-Lewis and Butler, 1997).

Model scenario 5 examines this possibility by augmenting non-QPS anthropogenic emissions to account entirely for the missing source (Table 3, Fig. 5). The missing source along with its seasonality is added to the agricultural emissions in each hemisphere. No additional missing source is included. This results in a larger decline in absolute emissions during the phase-out of anthropogenic methyl bromide. The biomass burning trend, $\mathrm{OH}$ trend, and phaseout rate are maintained as in scenario 4. Including the missing source in the non-QPS anthropogenic emissions results in a modelpredicted decline during phaseout more rapid than observed, and lower concentrations than observed at the end of the record (Fig. 5e). This result suggests it is not likely that the missing source can be accounted for entirely by an underestimation of the mean release fraction of industrial $\mathrm{CH}_{3} \mathrm{Br}$ in non-QPS fumigation applications. For the missing source to be entirely anthropogenic, and for the model to reproduce the atmospheric trend, this source must consist of QPS emissions which are not subject to the phaseout. It is unlikely that QPS emissions were underestimated by nearly $100 \%$.

Model scenario 6 examines the effect of increasing the lifetime of $\mathrm{CH}_{3} \mathrm{Br}$ to reduce the "missing source" to half of the amount required to balance the 1996 budget $\left(18.5 \mathrm{Gg} \mathrm{yr}^{-1}\right.$ ) (Table 3, Fig. 5). This is done by reducing both the missing source and the soil uptake in each hemisphere relative to the best estimate 1996 budget. This results in an increase in the atmospheric lifetime to $0.84 \mathrm{yr}(\sim 13 \%$ 
increase over the best estimate). With the longer lifetime, the model also underestimates the seasonal amplitude of atmospheric $\mathrm{CH}_{3} \mathrm{Br}$, particularly in the northern hemisphere. Increasing the atmospheric lifetime still further to account for the entire missing source would lead to an even larger discrepancy in terms of the amplitude of the seasonal cycle. The phaseout of anthropogenic emissions results in an underestimate of atmospheric $\mathrm{CH}_{3} \mathrm{Br}$ levels after 2002 due to the loss of the remaining missing source, as it was included as an anthropogenic non-QPS emission in this scenario.

Scenario 7 assumes that the reduced global missing source described in scenario 6 is natural and does not decline with the anthropogenic phaseout (Table 3, Fig. 5). The lifetime is kept at $0.84 \mathrm{yr}$ as in scenario 6 . The seasonality of this missing source was optimized to try to achieve the pre-phaseout observed seasonal amplitude in the $\mathrm{CH}_{3} \mathrm{Br}$ burden (Fig. 4b). Other conditions are as in scenario 6. The model results exhibit fairly good agreement with the observations. However, as in scenario 4, the model overpredicts the atmospheric values after 2004 slightly. As in scenario 6, seasonal amplitudes pre-phaseout and post 2004 are underestimated. The longer atmospheric lifetime makes it impossible for the model to achieve the seasonal amplitude observed in the NH. Achieving the observed amplitude requires imposing a negative missing source at certain times of the year. That would effectively shorten the atmospheric lifetime back to the original value.

While the interannual variations in $\mathrm{OH}$ introduced in case 2 have an effect on the atmospheric $\mathrm{CH}_{3} \mathrm{Br}$ lifetime, this effect is very small and is largest for 1997/1998 with an approximately $0.04 \mathrm{yr}(<6 \%)$ increase in the lifetime for those two years (Fig. 5). After 1998, the $\mathrm{CH}_{3} \mathrm{Br}$ lifetime in the model gradually returns to the initial $0.75 \mathrm{yr}$ value. An increase in the lifetime large enough to account for only half of the missing source results in a seasonal amplitude that is smaller than observed pre-phaseout (Fig. $5 \mathrm{f}$ and g). The missing source is not likely the result of overestimated sinks.

Scenario 8 involves increasing the escape rate of agricultural $\mathrm{CH}_{3} \mathrm{Br}$ to $60 \%$ of the amount applied rather than the 50\% assumed in scenarios 1-4 (Table 3, Fig. 5). This increases the anthropogenic to total emission fraction to $\sim 28 \%$ which is closer to the estimate of $30(20-40) \%$ given by Clerbaux and Cunnold (2007). The lifetime is the same as in scenarios $1-5(\sim 0.75 \mathrm{yr})$. The missing source in each hemisphere is reduced by the amount that the agricultural emission increased and seasonality was adjusted to match the 1995-1998 tropospheric mixing ratios $(\mathrm{NH}=10.2 \mathrm{ppt}, \mathrm{SH}=8.0 \mathrm{ppt}$ ) and seasonalities (Montzka et al., 2003) (Fig. 4c). This revised pre-phaseout budget is given in Table 1 as the 1996 (60\% Ag) budget. The prescribed interannual variations in biomass burning emissions, reaction with $\mathrm{OH}$, and anthropogenic emissions are the same as in scenario 4. By maintaining the original lifetime, the seasonal amplitude of the atmospheric $\mathrm{CH}_{3} \mathrm{Br}$ is closer to the observed seasonality for the entire simulation. The 1997
Southern hemispheric concentrations are elevated compared to observations, as in scenario 4 . The predicted concentrations from 2002-2007 are in better agreement with the observations than in any other scenario. The budget for 2007 from this scenario is shown in Table 1 as 2007 (60\% Ag), and the anthropogenic to total emission fraction decreased to $\sim 13 \%$.

\subsection{Ocean saturation state}

In this study, oceanic $\mathrm{CH}_{3} \mathrm{Br}$ production (magnitude, geographic distribution, and seasonality) was calculated for 1996 conditions. This oceanic production was held constant for the duration of all model runs, as were the kinetic parameters affecting oceanic $\mathrm{CH}_{3} \mathrm{Br}$ cycling (wind speeds, mixed layer depths, surface ocean temperature, and biological degradation rate constants). Although oceanic production was held constant, the saturation state of the oceans with respect to the overlying atmosphere varies in the model runs as a function of the atmospheric $\mathrm{CH}_{3} \mathrm{Br}$ levels, and the internal cycling of $\mathrm{CH}_{3} \mathrm{Br}$ within the oceans. Figure $6 \mathrm{a}$ shows the time series of oceanic $\mathrm{CH}_{3} \mathrm{Br}$ saturation state calculated in scenario 8 . The decrease in the calculated saturation anomaly for 1997 and 1998 results from the increase in atmospheric burden caused by increased biomass burning emissions and decreased $\mathrm{OH}$ concentrations in the model. The saturation state of the oceans increased substantially during the phaseout period in the model, shifting from a saturation anomaly (deviation from equilibrium) of $-11.7 \%$ in 1996 to $-6.0 \%$ in 2007 (Fig. 6a). The saturation anomaly decreased slightly during 2005 due to the increase in modeled atmospheric $\mathrm{CH}_{3} \mathrm{Br}$ concentrations resulting from increased QPS emissions, most notably in the southern hemisphere. Before phaseout, the northern hemisphere was more undersaturated than the southern hemisphere. This reversed during the first year of phaseout in the model, likely as a result of the much greater decline in emissions from the northern hemisphere.

The model results indicate that the oceans in both hemispheres, should now be closer to equilibrium than before the phaseout began. In fact, the model results indicate that the net flux is now positive (from sea to air) in the summer in each hemisphere. The global average net flux in 2007 is predicted to be $-6.6 \mathrm{Gg} \mathrm{yr}^{-1}$, less than half the pre-phaseout global average of $-14.0 \mathrm{Gg} \mathrm{yr}^{-1}$ (Fig. 6b). Most of the published saturation anomaly measurements for $\mathrm{CH}_{3} \mathrm{Br}$ in the open ocean were conducted during pre-phaseout conditions (King et al., 2002), and there are insufficient data from the phaseout period for comparison. Saturation anomaly measurements across the major ocean basins during different seasons should be carried out to test this prediction and validate current models of oceanic cycling. 

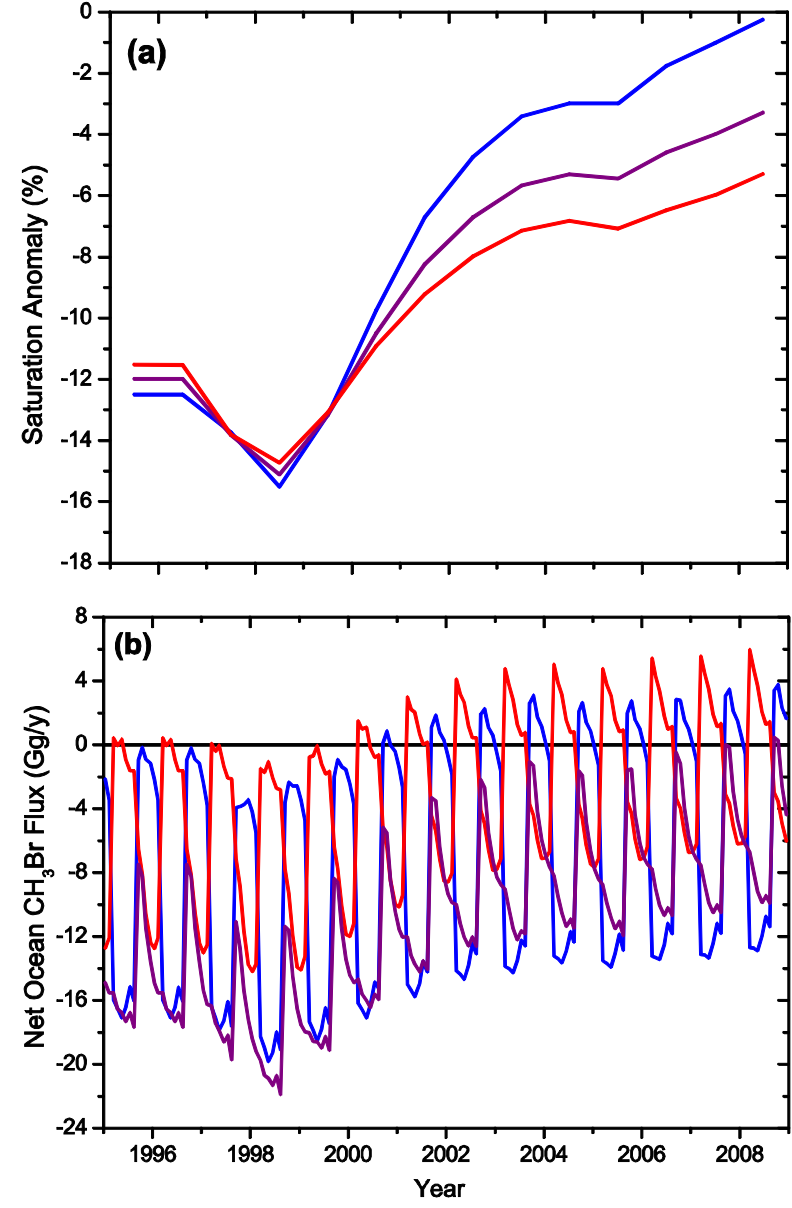

Fig. 6. From scenario 8, model predicted (a) annual average saturation anomaly (difference from equilibrium) of $\mathrm{CH}_{3} \mathrm{Br}$ in the ocean and (b) net ocean fluxes for the southern hemisphere (red line), the northern hemisphere (blue line), and the globe (purple line).

\section{Conclusions}

The observed decrease in atmospheric $\mathrm{CH}_{3} \mathrm{Br}$ resulting from the Montreal Protocol places new constraints on the global $\mathrm{CH}_{3} \mathrm{Br}$ budget. This study suggests that a portion ( $\sim 7 \mathrm{Gg} \mathrm{yr}^{-1}$ or about $20 \%$ ) of the $\mathrm{CH}_{3} \mathrm{Br}$ missing source is likely the result of underestimated anthropogenic fumigation emissions. The remainder $\left(\sim 31 \mathrm{Gg} \mathrm{yr}^{-1}\right.$ or about $\left.80 \%\right)$ is not likely due to underestimation of the agricultural emissions and is not likely to be the result of overestimated sinks (underestimated lifetime). Increasing agricultural sources beyond a $60 \%$ escape rate does not yield an improved agreement with the observed atmospheric rate of decline even when the lifetime is increased (Fig. 5, scenario 5 and 6). The best estimate lifetime (0.7-0.8 years) and larger missing source are necessary to maintain the large observed seasonal amplitude both before the phaseout and after 2002. Assuming constant production of $\mathrm{CH}_{3} \mathrm{Br}$ in the oceans, the de- creasing atmospheric levels imply a substantial increase in the saturation state of the oceans. The resulting change in air/sea flux represents an additional $7.4 \mathrm{Gg}$ in net flux to the atmosphere from the ocean in 2007, relative to pre-phaseout conditions.

We conclude from this study that the behavior of the atmospheric $\mathrm{CH}_{3} \mathrm{Br}$ burden over the phaseout period is reasonably consistent with our current understanding of the global budget which includes a substantial unidentified source. Interannual variations in the atmospheric burden are sensitive not only to the anthropogenic phaseout but also to variations in biomass burning emissions and $\mathrm{OH}$ radical concentrations. The anthropogenic contribution to the global budget, approximately $28 \%$ of total emissions in the best case scenario, is consistent with the latest assessment (Clerbaux and Cunnold, 2007). The lifetime of 0.7-0.8 yr is also consistent with the best estimate (Yvon-Lewis and Butler, 1997). There remains a significant imbalance in the global budget, which is likely due to unknown or underestimated natural sources that exhibit little interannual variability, as shown by the model. Additional field and modeling studies are needed in order to better constrain the $\mathrm{CH}_{3} \mathrm{Br}$ source from terrestrial ecosystems, particularly in the tropics. The detailed nature of the ocean model coupled to the simple atmospheric model along with the results from this study also highlight the need for new measurements of oceanic $\mathrm{CH}_{3} \mathrm{Br}$ saturation anomalies, to provide a comparison of pre-phaseout and current conditions to validate current models of oceanic cycling.

Acknowledgements. We would like to thank J. Butler, D. King, R. Tokarczyk, and M. Prather for innumerable insightful discussions, and G. van der Werf and J. Randerson for use of their biomass burning estimates. This research was supported by the National Science Foundation (OPP-0636953 and ATM0614816), the National Oceanic and Atmospheric Administration (NA06OAR4310049) and the Atmospheric Composition and Climate Program of NOAA's Climate Program Office.

Edited by: W. T. Sturges

\section{References}

Andreae, M. O. and Merlet, P.: Emission of trace gases and aerosols from biomass burning, Global Biogeochem. Cy., 15(4), 955-966, 2001.

Buffin, D.: Methyl bromide exemptions flout rules of Montreal Protocol, Pesticides News, 64, 18-19, 2004.

Clerbaux, C., Cunnold, D. M., Anderson, J., Engel, A., Fraser, P. J., Mahieu, E., Manning, A., Miller, J., Montzka, S. A., Nassar, R., Prinn, R., Reimann, S., Rinsland, C. P., Simmonds, P., Verdonik, D., Weiss, R., Wuebbles, D., and Yokouchi, Y.: Long-lived compounds, Chapter 1 in Scientific Assessment of Ozone Depletion: 2006, Global Ozone Research and Monitoring Project-Report No. 50, World Meteorological Organization, Geneva, 2007.

Cramer, W., Bondeau, A., Woodward, F. I., Prentice, I. C., et al.: Global response of terrestrial ecosystem structure and function to 
$\mathrm{CO}_{2}$ and climate change: results from six dynamic global vegetation models, Global Change Biol., 7, 357-373, 2001.

Dimmer, C. H., Simmonds, P. G., Nickless, G., and Bassford, M. R.: Biogenic fluxes of halomethanes from Irish peatland ecosystems, Atmos. Environ., 35, 321-330, 2001.

Erbrecht, T. and Lucht, W.: Impacts of large-scale climatic disturbances on the terrestrial carbon cycle, Carbon Balance Management, 1(7), doi:10.1186/1750-0680-1-7, 2006.

Federal Register: Department of Agriculture, Animal and Plant Health Inspection Service, Importation of Wood Packaging Material, 69 Federal Register 179, 16 September, 55719-55733, 2004.

Gan, J., Yates, S. R., Ohr, H. D., and Sims, J. J.: Production of methyl bromide by terrestrial higher plants, Geophys. Res. Lett., 25, 3595-3598, 1998.

IPPC: International Standards for Phytosanitary Measures, ISPM No.15., Guidelines for Regulating Wood Packaging Material in International Trade, Secretariat of the International Plant Protection Convention, FAO, Rome, 2002.

King, D. B., Butler, J. H., Yvon-Lewis, S. A., and Cotton, S. A.: Predicting oceanic methyl bromide saturation from SST, Geophys. Res. Lett., 29(24), 2199, doi:10.1029/2002GL016091, 2002.

Lee-Taylor, J. M. and Holland, E. A.: Litter decomposition as a potential natural source of methyl bromide, J. Geophys. Res., 105, 8857-8864, 2000.

Lelieveld, J., Brenninkmeijer, C. A. M., Joeckel, P., Isaksen, I. S. A., Krol, M. C., Mak, J. E., Dlugokencky, E., Montzka, S. A., Novelli, P. C., Peters, W., and Tans, P.P.: New Directions: Watching over tropospheric hydroxyl, Atmos. Environ., 40, 5741-5743, 2006.

MBTOC: United Nations Environment Programme (UNEP) Methyl Bromide Technical Options Committee (MBTOC) 2006 Assessment of the Alternatives to Methyl Bromide, United Nations Environment Programme, Nairobi, 453pp., 2006. (http://ozone. unep.org/teap/Reports/MBTOC/index.shtml)

Matthews, E.: Global vegetation and land use: New high-resolution databases for climate studies, J. Clim. Appl. Meteorol., 22, 474487, 1983.

Meeson, P. J., Corprew, F. E., McManus, J. M. P., Mayers, D. M., Closs, J. W., Sun, K.-J., Sunday, D. J., and Sellers, P. J.: ISLSCP Initiative I-Global data sets for land-atmosphere models, 19871988 (CD-ROM), vol. 1-5, USA_NASA_GDAAC_ISLSCP_001USA_NASA_GDAAC_ISLSCP_005, http://daac.gsfc.nasa.gov/, Distrib. Active Arch. Cent., Greenbelt, Md., 1995.

Montzka, S. A., Butler, J. H., Hall, B. D., Mondeel, D. J., and Elkins, J. W.: A decline in tropospheric organic bromine, Geophys. Res. Lett., 30, 1826, doi:1810.1029/2003GL017745, 2003.

Montzka, S. A., Fraser, P. J., Butler, J. H., Connell, P. S., Cunnold, D. M., Daniel, J. S., Derwent, R. G., Lal, S., McCulloch, A., Oram, D. E., Reeves, C. E., Sanhueza, E., Steele, L. P., Velders, G. J. M., Weiss, R. F., and Zander, R. J.: Controlled substances and other source gases, Chapter 1 in Scientific Assessment of Ozone Depletion: 2002, Global Ozone Research and Monitoring Project-Report No. 47, World Meteorological Organization, Geneva, 2003.

Nemani, R. R., Keeling, C. D., Hashimoto, H., Jolly, W. M., Piper, S. C., Tucker, C. J., Myneni, R. B., and Running, S. W.: ClimateDriven Increases in global terrestrial net primary production from
1982 to 1999 , Science, 300,1560 , doi:10.1126/science.1082750, 2003.

Prinn, R. G., Huang, J., Weiss, R. F., Cunnold, D. M., et al.: Evidence for variability of atmospheric hydroxyl radicals over the past quarter century, Geophys. Res. Lett., 32, L07809, doi:10.1029/2004GL022228, 2005.

Redeker, K. R., Wang, N. Y., Low, J. C., McMillan, A., Tyler, S. C., and Cicerone, R. J.: Emissions of methyl halides and methane from rice paddies, Science, 290, 966-969, 2000.

Reeves, C. E.: Atmospheric budget implications of the temporal and spatial trends in methyl bromide concentration, J. Geophys. Res., 108, 4343, doi:10.1029/2002JD002943, 2003.

Rhew, R. C., Miller, B. R., and Weiss, R. F.: Natural methyl bromide and methyl chloride emissions from coastal salt marshes, Nature, 403, 292-295, 2000.

Rhew, R. C., Miller, B. R., Vollmer, M. K., and Weiss, R. F.: Shrubland fluxes of methyl bromide and methyl chloride, J. Geophys. Res., 106, 20875-20882, 2001.

Saltzman, E. S., Aydin, M., De Bruyn, W. J., King, D. B., and Yvon-Lewis, S. A.: Methyl bromide in preindustrial air: Measurements from an Antarctic ice core, J. Geophys. Res., 109, D05301, doi:10.1029/2003JD004157, 2004.

Sander, S. P., Finlayson-Pitts, B. J., Friedl, R. R., Golden, D. M., Huie, R. E., Keller-Rudek, H., Kolb, C. E., Kurylo, M. J., Molina, M. J., Moortgat, G. K., Orkin, V. L., Ravishankara, A. R. and Wine, P. H.: "Chemical Kinetics and Photochemical Data for Use in Atmospheric Studies, Evaluation Number 15", JPL Publication 06-2, Jet Propulsion Laboratory, Pasadena, 2006.

Sellers, P. J., Meeson, P. W., Closs, J., Collatz, J., et al.: An overview of the ISLSCP Initiative I global data sets for land-atmosphere models, 1987-1988, vol. 1-5, vol. 1: USA_NASA_GDAAC_ISLSCP_001, OVERVIEW.DOC, http:// daac.gsfc.nasa.gov/, Distrib. Active Arch. Cent., Greenbelt, Md., 1995.

Shorter, J. H., Kolb, C. E., Crill, P. M., Kerwin, R. A., Talbot, R. W., Hines, M. E., and Harriss, R. C.: Rapid degradation of amtopsheric methyl bromide in soils, Nature, 377, 717-719, 1995.

Spivakovsky, C. M., Logan, J. A., Montzka, S. A., Balkanski, Y. J., Foreman-Fowler, M., Jones, D. B. A., Horowitz, L. W., Fusco, A. C., Brenninkmeijer, C. A. M., Prather, M. J., Wofsy, S. C., and McElroy, M. B.: Three-dimensional climatological distribution of tropospheric OH: update and evaluation, J. Geophys. Res., 105, 8931-8980, 2000.

Thomas, V. M., Bedford, J. A., and Cicerone, R. J.: Bromine emissions from leaded gasoline, Geophys. Res. Lett., 24, 1371-1374, 1997.

UNEP: Report of the seventh meeting of the parties to the Montreal Protocol on Substances that Deplete the Ozone Layer, United Nations Environmental Program, World Meteorol. Org. (WMO), Geneva, Dec., 1995.

van der Werf, G. R., Randerson, J. T., Collatz, G. J., Giglio, L., Kasibhatla, P. S., Arellano Jr., A. F., Olsen, S. C., and Kasischke, E. S.: Continental-Scale Partitioning of Fire Emissions During the 1997 to 2001 El Niño/La Niña Period, Science, 303, 73-76, 2004.

van der Werf, G. R., Randerson, J. T., Giglio, L., Collatz, G. J., Kasibhatla, P. S., and Arellano Jr., A. F.: Interannual variability in global biomass burning emissions from 1997 to 2004, Atmos. Chem. Phys., 6, 3423-3441, 2006, 
http://www.atmos-chem-phys.net/6/3423/2006/.

Varner, R. K., Crill, P. M., and Talbot, R. W.: Wetlands: a potentially significant source of atmospheric methyl bromide and methyl chloride, Geophys. Res. Lett., 26(16), 2433-2436, 1999.

Warwick, N. J., Pyle, J. A., and Shallcross, D. E.: Global modeling of the atmospheric methyl bromide budget, J. Atmos. Chem., 54, 133-159, doi:10.1007/s10874-006-9020-3, 2006.

Yevich, R. and Logan, J. A.: An assessment of biofuel use and burning of agricultural waste in the developing world, Global Biogeochem. Cy., 17(4), 1095, doi:10.1029/2002GB001952, 2003.
Yokouchi, Y., Toon-Sauntry, D., Yazawa, K., Inagaki, T., and Tamaru, T.: Recent decline of methyl bromide in the troposphere, Atmos. Environ., 36, 4985-4989, 2002.

Yvon-Lewis, S. A. and Butler, J. H.: The potential effect of oceanic biological degradation on the lifetime of atmospheric $\mathrm{CH}_{3} \mathrm{Br}$, Geophys. Res. Lett., 24, 1227-1230, 1997.

Yvon-Lewis, S. A. and Butler, J. H.: Effect of oceanic uptake on atmospheric lifetimes of selected trace gases, J. Geophys. Res., 107, 4414, doi:10.1029/2001JD001267, 2002. 